US Army Corps of Engineers $s_{\circledast}$

Engineer Research and

Development Center

\title{
Challenges in Evaluating Efficacy of Scientific Visualization for Usability and Aesthetics
}

Julie Baca, Daniel W. Carruth, Alex Calhoun,

May 2021

Michael Stephens, and Christopher Lewis 
The U.S. Army Engineer Research and Development Center (ERDC) solves the nation's toughest engineering and environmental challenges. ERDC develops innovative solutions in civil and military engineering, geospatial sciences, water resources, and environmental sciences for the Army, the Department of Defense, civilian agencies, and our nation's public good. Find out more at www.erdc.usace.army.mil.

To search for other technical reports published by ERDC, visit the ERDC online library at https://erdclibrary.on.worldcat.org/discovery. 


\section{Challenges in Evaluating Efficacy of Scientific Visualization for Usability and Aesthetics}

Julie Baca, Michael Stephens, and Christopher Lewis

Information Technology Laboratory

U.S. Army Engineer Research and Development Center

3909 Halls Ferry Road

Vicksburg, MS 39180

Daniel W. Carruth and Alex Calhoun

Center for Advanced Vehicular Systems

Mississippi State University

75 B. S. Hood Road

Starkville, MS 39762

Final report

Approved for public release; distribution is unlimited.

Prepared for U.S. Army Corps of Engineers

Washington, DC 20314-1000

Under BAA Contract Number W912HZ-17-C-0015, Task 4 


\section{Preface}

This study was conducted for the U.S. Army Corps of Engineers (USACE), under BAA funding, Contract Number W912HZ-17-C-0015, Task 4.

The work was performed by the Supercomputing Research Center, U.S. Army Engineer Research and Development Center, Information Technology Laboratory (ERDC-ITL). At the time of publication of this Miscellaneous Paper, Mr. Robert Alter was DSRC Deputy Director and Mr. Robert Hunter was SRC Chief/DSRC Director. The Deputy Director of ERDC-ITL was Ms. Patti S. Duett and the Director was Dr. David A. Horner.

This paper was originally published online as part of the International Conference on Human-Computer Interaction on 4 July 2019 and published in Design, User Experience, and Usability. Practice and Case Studies. Lecture Notes in Computer Science.

The Commander of ERDC was COL Teresa A. Schlosser and the Director was Dr. David W. Pittman.

DISCLAIMER: The contents of this report are not to be used for advertising, publication, or promotional purposes. Citation of trade names does not constitute an official endorsement or approval of the use of such commercial products. All product names and trademarks cited are the property of their respective owners. The findings of this report are not to be construed as an official Department of the Army position unless so designated by other authorized documents. 


\title{
Challenges in Evaluating Efficacy of Scientific Visualization for Usability and Aesthetics
}

\begin{abstract}
This paper presents the results of a study to evaluate the efficacy of scientific visualization for multiple categories of users, including both domain experts as well as users from the general public. Efficacy wa s eva luated for understanding, usability, and aesthetic value. Results indica te that aesthetics play a critical, but complex role in enhancing both user understanding and usability.
\end{abstract}

\section{Introduction}

Eva luating the efficacy of scientific visualization has long presented challenges to those working in the field, whether users, crea tors, or providers. Early resea rch focused on honing specific visualization techniques and underly ing a lgorithms [1,2]. As the technology matured, higher level user-centered efforts to evaluate scientific visualization began to appear [3-6].

A recent comprehensive review of evaluation practices in scientific visualization is given in [7]. The review encodes papers from 10 years of IEEE Visualization conferences to assess their evaluation practices. While reports of evaluation per se steadily rose during the review period, the sa me did not hold true with respect to user involvement in evaluations. Of the encoded papers, over $95 \%(955 / 1002)$ did not include users in a structured evaluation, but instead either 1) presented readers of papers with image or a lgorithm enhancements, asking them to assess any im provements for themselves or 2) relied on reports of feedback a informal demos to expert users [7].

Our study seeks to a ddress these ga ps by engaging multiple categories of potential actualusers in formally evaluating the efficacy of scientific visualization.

\section{Background}

\subsection{Evaluation TestBed}

Our work providing visualization services to scientists in the DoD High Performance Computing Modernization Program(HPCMP) motivated the need to evaluate scientific visua lization from our users' many potential perspectives. We offer support to scientists analyzing large volumes of complex data in a variety of ways, including but not 
limited to a ssistance in using a visualization technique, as well a s choosing which technique to use for a particular problem. Support may also involve a visualization specialist colla borating with the scientist in the use of the visualization program to extract data or images that high light problems with an original computation.

Our users often need the visualization results to communicate and collaborate with other experts in their field to solve problems, but also to convey the results of their work to non-expert users who function as sponsors or lia isons to funding agencies. In a ddition, they must share their research for the purposes of outreach and education of the general public not trained in their resea rch areas.

Hence, the two basic informational and communicative needs of our direct users can be broa dly categorized a :

- $\quad$ Collaborating with other experts in their fields to conduct research;

- $\quad$ Communicating results to non-expert sponsors or public consumers

We designed our study to include both of these ca tegories of users.

\subsection{Related Research}

Three types of evaluations conducted in the field of information visualization are relevant to our study and informed our a pproach:

1. Usability-centered

2. Aesthetic

3. Iterative, generative designed-based

Usability-centered evaluations a ssess ea se-of-use through objective measurement of user task performance, as well as subjective measures of user satisfaction $[8,9]$. Aesthetic evaluations focus specifically on measuring the user's perception of a esthetic quality of a graphic element or visualization, either through objectively quantifiable metrics, such as the number of bends or edgesin a graph [10] or through personaljudgments of beauty [11].

Itera tive, designed-based evaluations use any results gained in an itera tive feedback loop to refine or enhance a visualization or other UI as it is being developed $[12,13]$. Any of these categories of evaluations may overlap or be used in parallel in a given study, as for example in $[14,15]$ to examine effects of a esthetics on usability. Of particular relevance to our research, the aesthetic evaluations in these studies based certain key hypotheses of expected user responses on the work of Tufte [16] who argued that the human eye finds nature's pa lette most harmonious, and that blues, greens, and browns would have the most desirable impact in information display. Additionally, the presence of any organic, lifelike movement or a nimation, such as that found in nature, would provide further benefit.

Our study uses a spects of evaluation types 1 and 2 , with the goal of using the results going forward in the type 3 designed-based evaluations that allow enhancement of a visua lization as it is developing. 


\section{Methods}

Approximately 30 users from each category, expert and non-expert, participated in the study. Participants were recruited from a mong faculty, general staffa nd students at a university research center. They were a sked to watch videos of a scientific visualization, answer questions about its content, and to evaluate its aesthetic quality. They were also a sked to ra te their perception of the impact of the work visualized for science and the military.

\subsection{Visualization Description}

The Army is studying heavy fuel engines relying exclusively on direct injection fuel delivery systems. To meet requirements, theengines must significantly advance current fuel flexibility and fuel conversion efficiencies. In propulsion systems, energy conversion by combustion relies on the use of jet fuel in the compressed liquid form. The initial step in the energy conversion process is the a tomization, or disintegration of the coherent liquid core, which significantly impacts the droplet-size distribution and fuel conversion efficiency. In combusting scenarios, the liquid fuel must be fully a tomized, evaporated and mixed with the carrier ga s-phase environment. Hence, the interaction of liquid a tomization and spray vaporization is critical, as it determines the level of energy and fuel supplied to the flame.

Also relevant to our work were emails exchanged with the visualization staff regarding the principal investigator's intent for his audience in creating the visua lization, as shown in the excerpt below:

"In the visualization, I'd like to high light the a tomization breakup features of the spray, that is, surface instability corrugations, liga ment formation, spray development. Perhaps a transparent media (color) would a lso show the internal flow structure. I'm open to your ex pert suggestions a s well.”

Users in the study were shown an a nimation of the visualization of the atomization spray that was subsequently created iteratively with our visualization team and the resea rcher. Key frames of the animation illustrating the a tomization process are shown in Figures 1-5. 


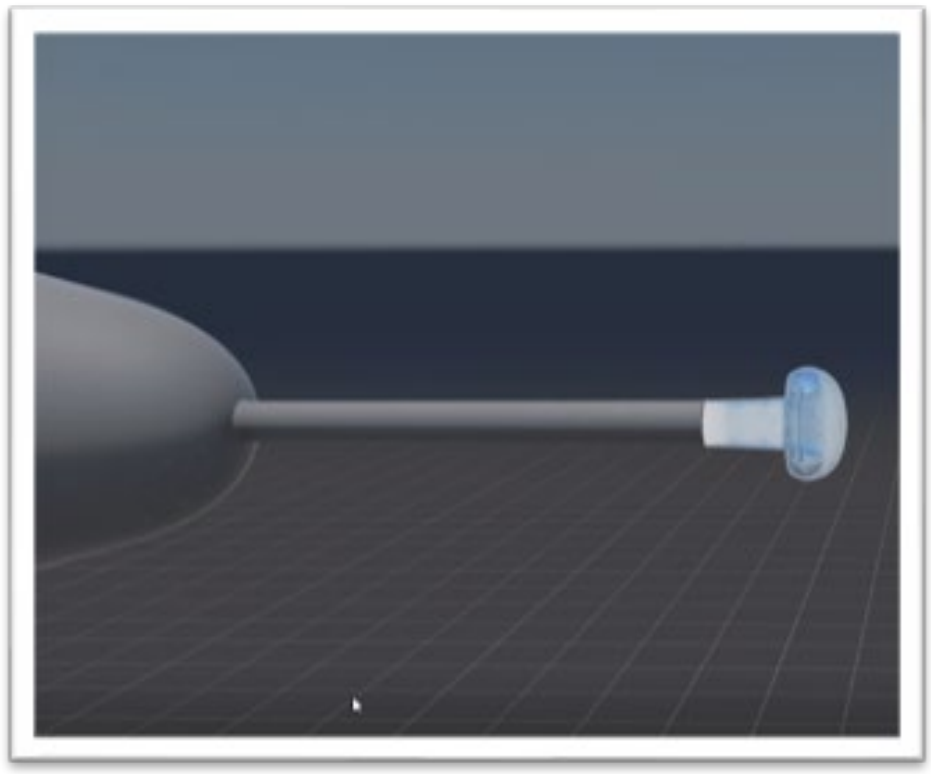

Fig. 1. Early fra me in energy conversion process

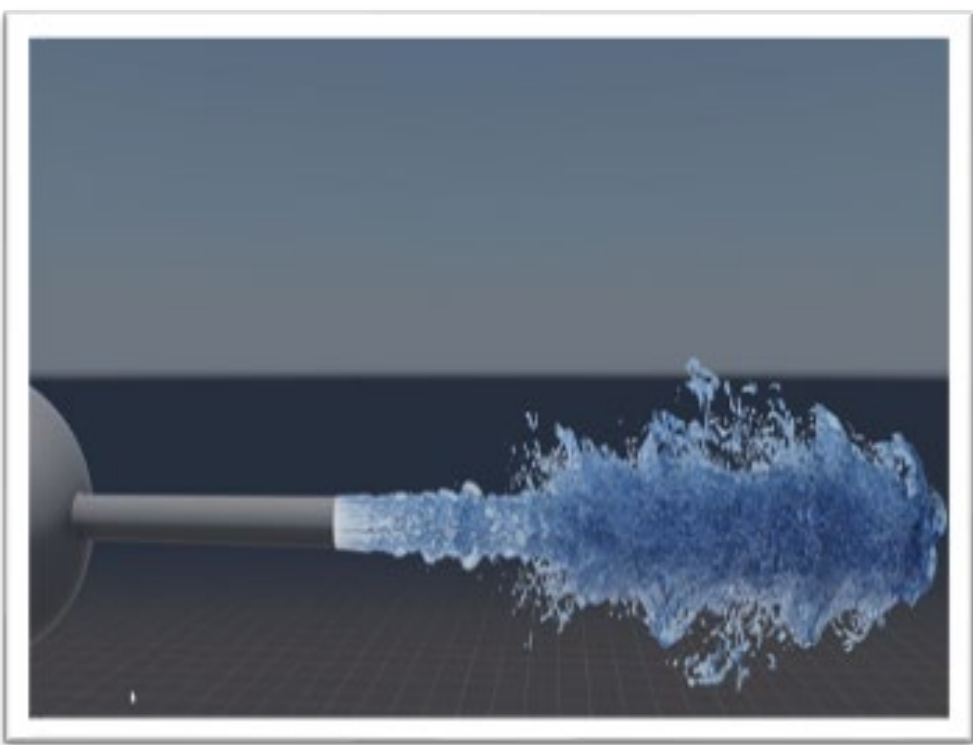

Fig. 2. Atomization spray droplets beginning to form 


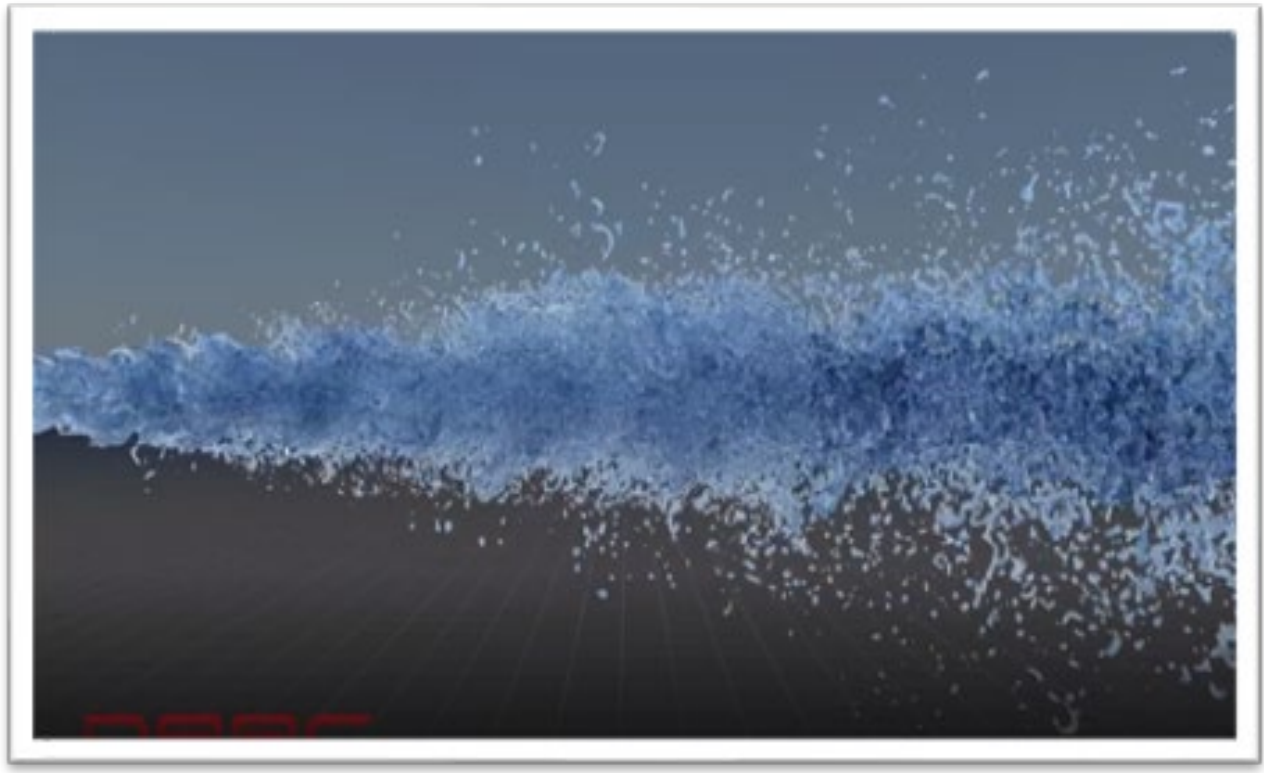

Fig.3. Atomization spray mid-animation

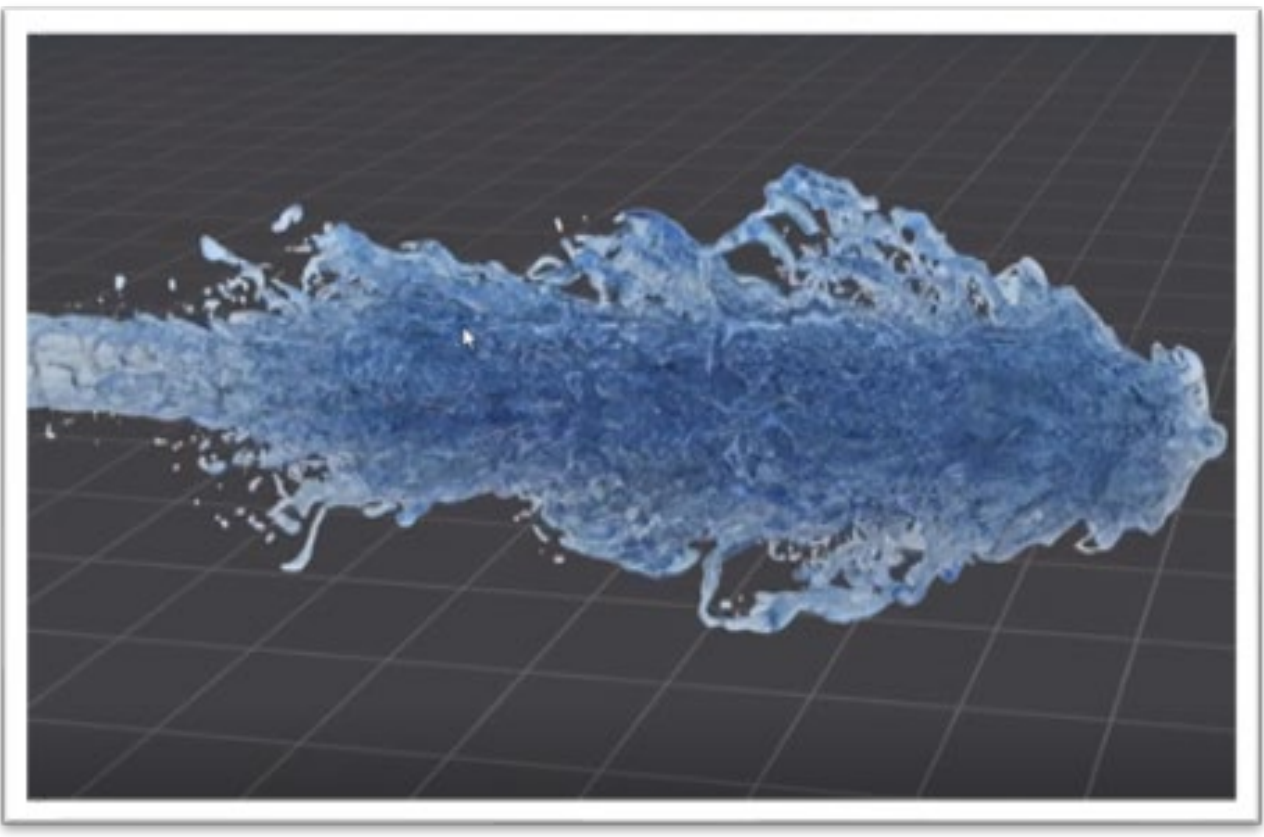

Fig. 4. Atomization spray la ter in animation 


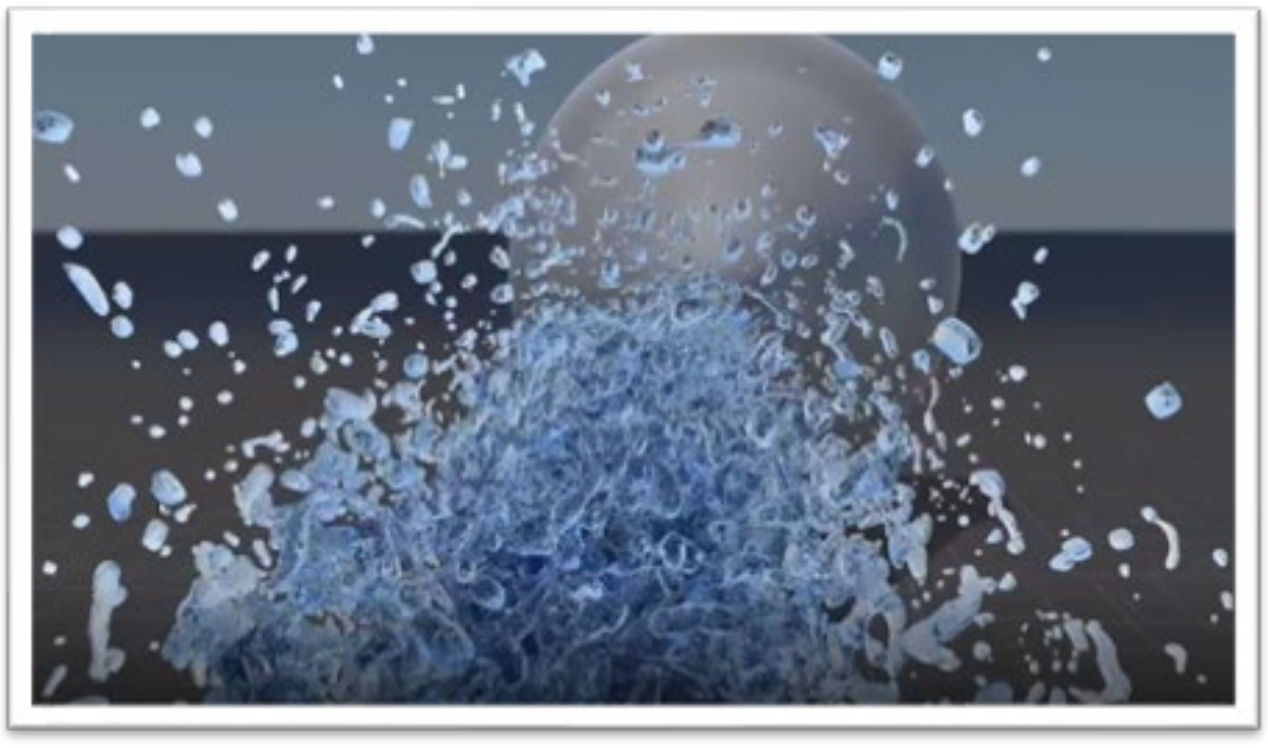

Fig.5. Atomization spray droplets final a nimation frame

\subsection{Experimental Treatments}

Users viewed the set of visualizations of the a tomization and spray vaporization interactions shown in Figures 1-5. They were a lso given a textual description of the entire process on the first screen shown. There were no "tasks" for users to perform in the tra ditional usability sense; however they were asked to answer questions about what they viewed rega rding content, impact and aesthetics. They were also asked to rate their confidence in their a nswers

Once they advanced beyond the first screen to answer questions, users were allowed to view the visua lizations a s many times a s they wished, but could no longer view the textual description for the remainder of the experim ent in order to isolate the effectiveness of the visualization itself. The rela tive completeness of their answers, and their confidence ratings, functioned as measures of task completion. The survey contained 8 questions regarding scientific content, its potential importance to science and the military, with 3 questions regarding users' confidence in their a nswers.

Users were a sked in 2 a dditional questions to ra te their perceptions of a esthetic quality of the visualizations and to give an explanation of their rating. Based on Tufte's assumptions [16], tested in [15], we expected that the spectrum of blues used in the visualization of the atomized spray, its similarity to the appearance of water, and the orga nic lifelike movement of the animation of the spray, would have a positive effect on user ra tings and explanations. 


\section{Results}

\subsection{Scoring Answers}

Scoring understanding of textual answers (i.e., non-numeric) involvesa subjective element. Multiple readers (3) provided scores for each answer. Inter-ra ter reliability for the 3 rea ders was calculated using Gwet's AC2 [17] and is reported in Ta ble 1. A final score wa s calculated by taking the a verage of the 3 scores.

Answers were scored on the following 3-point scale:

0 Wrong, absent, or irrelevant

1 Correct undetailed

2 Correct detailed

Overall results for accuracy of textual answers for the central problem, the main idea, and the impact of the research, as well as the user's confidence in their own answers and ratings is given in Table 1 .

Table 1. Overall results for accuracy and user confidence.

\begin{tabular}{lccc}
\hline & Accuracy (0-2) & Confidence (1-5) & Gwet AC2 \\
\hline & & & \\
Central Problem & 0.89 & 2.55 & .49 \\
Main Idea & 1.08 & 2.78 & .63 \\
Impact & 0.85 & 2.48 & .39 \\
& & & \\
\hline
\end{tabular}

Overall scores for other questions with numeric ratings that did not require users to write a descriptive answer included significance to science, importance to military, and perceived aesthetics. These scores a re shown in Table 2-3.

Table 2. Overall results for significance to science and importance to military

Least to Highest (1-5)

Significance to Science $\quad 3.63$

Importance to Military 4.3 
Table 3. Overall results for perceived aesthetics

Ugly to Beautiful $(0-100)$

\subsection{Analysis}

Several key questions motivated our research and guided our analysis of the results. Discussion and analysis for each question are presented below.

\section{Does perceived aesthetics predict perception of the significance of the research} to science?

Perceived a esthetics wa s correlated with individuals' a ssessment of the significance of the research to science, rho $=.432, \mathrm{p}<.01$. Participants who perceived the animation as more attractive were more likely to perceive the research as significant to science. An analysis of variance indicated that for every pointtowards beautiful, there was a .37 increa se in significance, $\mathrm{F}(1,39)=6.05, \mathrm{p}<.05$.

\section{Does perceived aesthetics affect understanding?}

Participant understanding of the impact of the research was also correlated with their perception of the aesthetics of the video, $r h o=-.356, p<.05$. Participants that felt the visua lization was less a ttractive were more likely to provide a n accurate assessment of impact.

\section{Does perception of a esthetics a ffect confidence in responses?}

The analysis revealed no evidence of a relationship between the aesthetics of the animation and participant self-reported confidence in their responses.

4. Does self-reported prior knowledge of underlying science or modeling and simulation predict accuracy of answers?

Participant self-reported prior knowledge did not predict understanding of the central problem $(\mathrm{p}=.34)$, impact $(\mathrm{p}=.31)$, or the ma in ideas presented $(\mathrm{p}=.78)$.

\section{Does self-reported prior knowledge of underlying science or modeling and sim-} ulation predict confidence? 
An analysis of variance indicates that self-reported knowledge of modeling and simulation combined with their understanding of the central problem does predict self-reported confidence in their understanding of the central problem $\mathrm{F}(4,39)=2.92, \mathrm{p}<.05$ ). By itself, there was no relationship between self-reported knowledge and the accuracy of their responses. There was no evidence that this relationship also applied to confidence in their understanding of the impact of the research, $\mathrm{F}(4,39)=1.13, \mathrm{p}=.36$ ), or of the main ideas presented in the video, $\mathrm{F}(4,39)=1.98, \mathrm{p}=.12$.

\section{Is understanding related to confidence in responses?}

Participant confidence in their understanding of the central problem was correlated with accuracy, rho $=-.342, \mathrm{p}<.05$, but participants with higher confidence in responses were actually less accurate. However, the analysis did not provide support for a relationship between confidence in understanding of the main ideas and the impact and accuracy in responses.

\section{Does understanding predict perceived importance to the military?}

Understanding of the central problem was negatively associated $(B=-.64)$ with the perceived importance to the military (better understanding led to less perceived importance), $\mathrm{F}(3,39)=3.29, \mathrm{p}<.05$.

In contrast, understanding of the main ideas presented in the visualiza tion wa s positively a ssociated $(\mathrm{B}=.48)$ with perceived importance of the research to military.

\section{Does understanding predict perceived significance to science?}

The accuracy of participants' understanding of the central problem, main ideas, and impact were not significant predictors of how significant the participants perceived the research to be to science.

\section{Will adherence to Tufte's guidelines on the use of organic qualities and colors found in nature positively affect user perceived aesthetics?}

Users' explanations for their a esthetic ra tings contained a relatively high number of positive comments (18/41, roughly $43 \%$ ) related to the color choice (blue) and/or the rea listic, lifelike qua lity of the a nimation of the liquid, including its similarity to water. Given the rela tively high overall a esthetic rating of ( 72.7 points out of 100$)$ this appears to support Tufte's recommendations. Examples of user comments are presented below:

U1: ". . ea sy on the eyes to visually understand where the fuel is going. It has good colors."

U2: "The gra phical imagery was realistic and the colors popped. The la st shot of the up-close visualization was stunning." 
U3: "I liked how the fuel was shot in slow motion and themany different views of that process given....The coloring was also nice."

U4: “...the blues and 3D patterns were cool."

U5: “...the colors and detail of the liquid a re attractive.

U6: "...the blue colors of the fuel were fairly visually pleasing and seem ed to demonstrate the a tomization and injection."

U7: “...the color choices help to distinguish the different regions of density process well."

\section{Conclusions}

The expectation that aesthetics might play a critical role in both user understanding of the content of the visualization as well as its usa bility was confirmed, but in more complex patterns than expected. Perceived aesthetics proved a predictor of user perception of the significance of research to science, i.e., "uglier" a esthetic ratings were correlated with lower user perceptions of research significance. In a ddition, perceived aesthetics affected user understanding of the impact of the research; however, higher or "more beautiful" a esthetic ratings were correlated with less a ccurate a ssessments of impact. However, aestheticswere not a significant predictor of user confidence in their ratings. Finally, tracking with Tufte's a ssertions [16], users' explanations for higher aesthetic ratings included a rela tively high number of comments $(18 / 41$, roughly $43 \%)$ related to the choice of natural, lifelike movement, i.e., wa ter, and/or the colors from nature, i.e., the colorblue.

Other key questions of the research regarding self-reported prior knowledgeproved complex as well. While this fa ct or did not predict user understanding, it wa s a predictor of user confidence, i.e. those with self-reported priorknowledge or expertise were more likely to report a high level of confidence in their ratings.

We plan to continue the research by expanding the study in several ways. First we plan to conduct another study using visua lizations providing more contextual information such as conceptual animations, and musical tracks to a ssess the levelat which these factors may affect the key questions regarding usability and understanding. Second, we plan to include comparison studies of the original researcher's visualization, which did not a dhere to Tuft's guidelines, a gainst the visualization created in collaboration with our visualization team.

Our long-term goal is to use the results of these studies during design and development to enhance the quality of visualizations provided to researchers, scientists, and the general public. This research will enable a more explicit formulation of a visualization usa bility process to follow to attain ourgoal. 


\section{Acknowledgements}

This material is based upon work supported by the U.S. Army TACOM Life Cycle Command under Contract No. W56HZV-08-C-0236.

\section{References}

1. Wong, C. and Bergeron, D.: 30 years of multidimensional multivariate visualization. [book auth.] G. Hagen, H. and Muller, H. Nielsen. Scientific Visualization. Los Ala mitos,CA, USA, IEEE Computer Society (1997).

2. Rheuter, L., Tukey, P., Maloney, L.T., Pani, J.R., Smith, S.: Human perception and visualization. Viz' 90 Proceedings of the 1 st Conference on Visualization '90, pp. 401-406, IEEE Computer Society Press, Sa Fra ncisco, CA, USA(1990).

3. Herndon, K., van Dam, A., and Gleicher, M: The challenges of 3D interaction: A CHI '94 Workshop. SIGCHI Bulletin 26 (4), 1-9 (2007).

4. Komlodi, A. Rehingans, P., Aya chit, U., Goodall, J., and Joshi, A.: A user-centered look at glyph-based security visualization. IEEE 2005 Workshop on Visua lization for Computer Security, pp. 21-28. IEEE, Minneapolis, MN, USA (2005).

5. Santos, B.S., Silva, S., Teixeira, L., Ferreira, C., Dia s, P., Madeira, J.: Preliminary usability evaluation of PolyMeCo: A visualization based tool for mesh analysis and comparison. Geometric Modeling and Imaging '07, pp. 133-139. IEEE, Zurich, Switzerland IEEE (2007).

6. Tory, M., Moller, T.: Evaluating visualizations: Do expert reviews work? IEEE Visualization Viewpoint in Computer Graphics and Applications. 25, 8-11 (2005).

7. Isenberg, T., Isenberg, P., Chen, J., Sedlmair, M., and Moller, T. A systematic review on the practice of evaluating visualization, IEEE Transactions on Visualization and Computer Graphics. 19(12), 2818-2827 (2013).

8. Nielsen, J. Usa bility Inspection Methods. New York: John Wiley \& Sons, (1994).

9. Norman, D.A., and S.W. Draper. User Centered System Design: New Perspectives on Human Computer Interaction. Hillsdale, NJ: Erlbaum (1986).

10. H. Purchase, J.A. Allder, and D. Carrington: Metrics for graph drawing aesthetics. .Journal of Visual La nguages and Computing 13,501-516,(2002).

11. Hartmann, J.: Assessing the a ttractiveness of interactive systems. In CHI '06 Extended Abstracts on Human Factors in Computing Systems, pp. 1755-1758. ACM Press, Montreal, Quebec, Canada (2006).

12. Preece, J., Rogers, Y., and Sharp, H.: The process of interaction design. Chap. In Interaction Design: Beyond Human-Computer Interaction. John Wiley \& Sons, New York, NY (2002).

13. Jackson, B., Coffeey, D., Thorsen, L., Schroeder, D., Ellingson, A.M., Nuckley, D.J., and D.F. Keefe.: Towards mixed method evaluations of scientific visualizationsand design process as an evaluation tool. BELIV 2012, Seattle Washington, USA(2012). 
14. Cawthon, N. and A. Vande Moere: Qualities of perceived aesthetic in da ta visua lization. CHI 2007, pp. 1-11. ACM Press, San Jose, USA (2007).

15. Cawthon, N and A. Vande Moere: The effect of aesthetic on the usability of data visua lization. 11th International Conference Information Visualization IV'07, pp. 637-648, IEEE Computer Society, Washington D.C., USA (2007).

16. E. Tuft:, Envisioning Information. Graphics Press, Cheshire, Conn. U.S.A. (1990).

17. K.L. Gwet: Handbook of Inter-Rater Reliability ( ${ }^{\text {rd }}$ Ed.). Advanced Analytics, LLC, Maryland. U.S.A. (2012). 


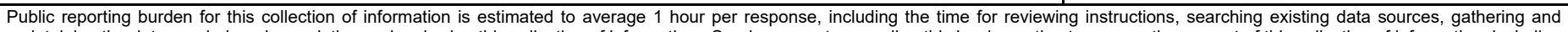

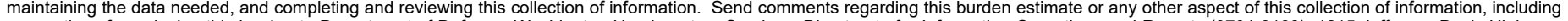

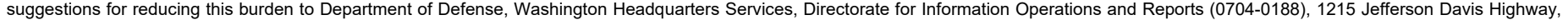

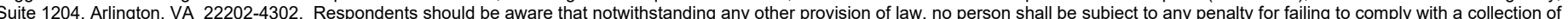

information if it does not display a currently valid OMB control number. PLEASE DO NOT RETURN YOUR FORM TO THE ABOVE ADDRESS.

\section{RTE (DD-MM-YYYY) May 2021}

\section{TITLE AND SUBTITLE}

Challenges in Evaluating Efficacy of Scientific Visualization for Usability and Aesthetics

\section{AUTHOR(S)}

Julie Baca, Daniel W. Carruth, Alex Calhoun, Michael Stephens, and Christopher Lewis

\section{PERFORMING ORGANIZATION NAME(S) AND ADDRESS(ES)}

U.S. Army Engineer Research \& Development Ctr Information Technology Laboratory 3909 Halls Ferry Road

Vicksburg, MS 39180

Center for Advanced Vehicular Systems Mississippi State University Starkville, MS 39762
3. DATES COVERED (From - To)

5a. CONTRACT NUMBER

W912HZ-17-C-0015

5b. GRANT NUMBER

5c. PROGRAM ELEMENT NUMBER

5d. PROJECT NUMBER

5e. TASK NUMBER

4

5f. WORK UNIT NUMBER

8. PERFORMING ORGANIZATION REPORT NUMBER

ERDC/ITL MP-21-8

10. SPONSOR/MONITOR'S ACRONYM(S)

11. SPONSOR/MONITOR'S REPORT NUMBER(S)

\section{DISTRIBUTION / AVAILABILITY STATEMENT}

Approved for public release; distribution is unlimited.

\section{SUPPLEMENTARY NOTES}

This paper was originally published online as part of the International Conference on Human-Computer Interaction on 4 July 2019.

\section{ABSTRACT}

This paper presents the results of a study to evaluate the efficacy of scientific visualization for multiple categories of users, including both domain experts as well as users from the general public. Efficacy was evaluated for understanding, usability, and aesthetic value. Results indicate that aesthetics play a critical, but complex role in enhancing both user understanding and usability.

\section{SUBJECT TERMS}

Scientific visualization, Usability, Aesthetics

16. SECURITY CLASSIFICATION OF:

\section{a. REPORT}

Unclassified

\section{b. ABSTRACT}

Unclassified c. THIS PAGE

Unclassified
17. LIMITATION OF ABSTRACT

SAR

\section{NUMBER} OF PAGES

\section{9a. NAME OF RESPONSIBLE} PERSON

19b. TELEPHONE NUMBER (include area code) 